University for Business and Technology in Kosovo

UBT Knowledge Center

UBT International Conference

2015 UBT International Conference

Nov 7th, 9:00 AM - 5:00 PM

\title{
The study of the multimodal level of service for the segment of urban road "Fehmi Lladrovci" in Prishtina
}

\author{
Makfiret Abdullahu \\ Prishtina Municipality, Department of Urban Planning, makfiretabdullahu@gmail.com \\ Jetmir Berisha \\ jetmirb@hotmail.com \\ Beni Kizolli \\ Gazi University, benikizolli@hotmail.com
}

Follow this and additional works at: https://knowledgecenter.ubt-uni.net/conference

Part of the Architecture Commons

\section{Recommended Citation}

Abdullahu, Makfiret; Berisha, Jetmir; and Kizolli, Beni, "The study of the multimodal level of service for the segment of urban road "Fehmi Lladrovci" in Prishtina" (2015). UBT International Conference. 62.

https://knowledgecenter.ubt-uni.net/conference/2015/all-events/62

This Event is brought to you for free and open access by the Publication and Journals at UBT Knowledge Center. It has been accepted for inclusion in UBT International Conference by an authorized administrator of UBT Knowledge Center. For more information, please contact knowledge.center@ubt-uni.net. 


\title{
The study of the multimodal level of service for the segment of urban road "Fehmi Lladrovci" in Prishtina
}

\author{
Makfiret Abdullahu1 ${ }^{1}$, Jetmir Berisha ${ }^{2}$, Beni Kizolli ${ }^{3}$ \\ ${ }^{1}$ Prishtina Municipality, Department of Urban Planning, Construction and Environmental \\ Protection \\ ${ }^{3}$ Transport and traffic in the Gazi University in Ankara/Turkey, \\ makfiretabdullahu@gmail.com ${ }^{1}$, \{jetmirb ${ }^{2}$, benikizolli $\left.{ }^{3}\right\} @$ hotmail.com
}

\begin{abstract}
The purpose of this study is to present the analysis for the urban road "Fehmi Lladrovci" in the city of Prishtina, aiming to identify the geometric and the intensity of a traffic flow factors which influences to the reduction of multimodal level of service. The study is focused in urban roads categories for the level like road "Fehmi Lladrovci" is, this road is one of the main roads of the city. Integral parts of this study are the models applied to calculation of multimodal level of service for each modes of traffic as vehicles, pedestrians, bicy cles and public transport based on NCHRP's rep ort and HCM 2010 manual. The impact of factors affecting multimodal level of service for all modes of road traffic are important elements and they affect the quality of level of service through urban roads. There are a lot of numbers of the participants moving on the road "Fehmi Lladrovci" which is located near the central zone, where along its extended collective housing with business premises. Based on the results obtained from this study recommendations for modifications are made for changing the width of the road, in order to increase the multimodal level of service to all modes of road traffic.
\end{abstract}

Keywords: multimodal level of service, the geometric factors, modes of traffic.

\section{Introduction}

Street "Fehmi Lladrovci" is located near the center of Pristina, which is a segment of the central city ring through which pass a large number of participants of traffic which extends through local collective housing business. Based on the importance and participation in relation to the city traffic we are determined to do a study to identify the multimodal level of service. This analy sis for segment of urban street "Fehmi Lladrovci" has resulted in the identification of factors affecting the flow of traffic, especially road geometric factors and the intensity of traffic flow factor. For this paper are applied the models for the calculation of multimodal level of service based on the $\mathrm{NCHRP}^{28}$ report and the $\mathrm{HCM}^{29} 2010$ manual. Results are recommendations for modification to change the cross section of the road within the existing width, in order to increase the multimodal level of service to all modes of composition of traffic.

\section{Models applied for calculation of the multimodal level of service}

For calculating the multimodal level of service are applied models which determine the multimodal level of service for vehicles, pedestrians, bicycles and public transport. Applied models are based on models published by the NCHRP report and HCM 2010 manual. These models include only the

\footnotetext{
28 NCHRP - National Cooperative Highway Research Program - addresses issues integral tothe state Departments of Transportation (DOTs) and transportation professionals at all levelsof government and the private sector.

${ }^{29} \mathrm{HCM}$ - Highway Capacity Manual - significantly enhance how engineers and planners assess the traffic and environmental effects of highway projects.
} 
calculation of multimodal level of service for segment of the road "Fehmi Lladrovci" between the two junctions that are roundabouts but that does not include the calculation of the intersections.

Calculating the level of service for vehicles is applied by two methods, the first by NCHRP's report which takes into account the geometric conditions of the road but not the intensity of traffic flow for vehicles and the percentage of commercial vehicles. While the second method which is under manual HCM 2010 takes into account important factors such as intensity of traffic flow, the capacity of the road, traffic density and geometric dimensions of the road.

Calculating the level of service for vehicles is done by the following equations:

Mean Auto LOS $=3.8-0.530($ Stops $)-0.155($ Median $)+0.355($ Left-Turn Lane $)+0.098($ Trees $)+$ 0.205 (Pavement Quality)

(1)

$D e=V p / S(a u / k m / l a n e)$

(2)

$S=B F F S-f_{L W}-f_{L C}-f_{M}-f_{A}$

(3)

Where:

Mean Auto LOS level of service for vehicles according to the NCHRP report.

De density of traffic for vehicles according to HCM 2010 manual

Vp Intensity of traffic flow

Speed limit

Calculating the level of service for pedestrians, bicycles adn public transport is made according to equations of NCHRP's report. The following equations are used for calculation of the multimodal level of service to the road segment:

$P L O S=-1.2276 \ln \left(f_{L V} x W t+0.5 W l+f p x \% O S P+f_{b} x W_{b}+f_{s w} x W_{s}\right)+$

$0.0091\left(V /\left(4 * P H F^{*} L\right)\right)+0.0004 S P D^{2}+6.0468$

(4)

$B S e g=0.507 \operatorname{Ln}(V /(4 * P H F * L))+0.199 F F^{*}(1+10.38 H V) 2+$

$7.066(1 / P C) 2-0.005(\mathrm{We}) 2+0.760$

(5)

Transit LOS Score $=6.0-1.50 *$ TransitWaitRideScore $+0.15 *$ PedLOS

(6)

Where:

PLOS the level of service for pedestrians

Bseg level of service for bicycles

Transit LOS Score level of service for public transport

In Table 1, numerical interval is given depending on the results obtained from the application of the relevant equations identified level of service for the type of movement which is dedicated equations applied by NCHRP's. In Table 2, numerical interval is provided depending on the density of traffic is defined level of service for vehicles which applies the HCM 2010 manual.

Table 1. Determining the multimodal level of service to all modes of traffic by NCHRP

\begin{tabular}{cc}
\hline MLS & Numerical Intervals \\
\hline A & $\leq 2.00$ \\
B & $>2.00 \leq 2.75$ \\
C & $>2.75 \leq 3.50$ \\
D & $>3.50 \leq 4.25$ \\
E & $>4.25 \leq 5.00$ \\
F & $>5.00$ \\
\hline
\end{tabular}

Table 2. Intervals of traffic density in determining the level of service for vehicles according to HCM 2010. 


\begin{tabular}{ccccccc}
\hline & \multicolumn{1}{c}{} & & & & \\
\hline $\begin{array}{c}\text { Level of } \\
\text { Service }\end{array}$ & A & B & C & D & E & F \\
\hline $\begin{array}{c}\text { Density } \\
\text { (AU/km/lane) }\end{array}$ & $0-11$ & $>11-18$ & $>18-26$ & $>26-35$ & $>35-45$ & $>45$ \\
\hline
\end{tabular}

\section{The analysis for traffic data and geometric conditions of the road}

The models applied for calculating the multimodal level of service required to analyze the traffic capacity for participants and geometric dimensions of the road being studied. Size image of the movement is made for three days of the week: Wednesday, Thursday and Friday, and is averaged traffic capacity. To be closer to identifying the level of service for segment of the road "Fehmi Lladrovci" recordings were made in three intervals of the day and in both directions of movement as indicated in Table 3.

Table 3. Traffic Capacity for the road "Fehmi Lladrovci"

\begin{tabular}{|c|c|c|c|c|c|c|}
\hline $\begin{array}{l}\text { Time } \\
\text { interval }\end{array}$ & $\begin{array}{l}\text { 7:00 to } \\
8: 00\end{array}$ & $\begin{array}{l}\text { 7:00 to } \\
8: 00\end{array}$ & $\begin{array}{l}12: 00 \text { to } \\
13: 00\end{array}$ & $\begin{array}{l}12: 00 \text { to } \\
13: 00\end{array}$ & $\begin{array}{l}16: 00 \text { to } \\
17: 00\end{array}$ & $\begin{array}{l}16: 00 \text { to } \\
17: 00\end{array}$ \\
\hline $\begin{array}{l}\text { Types } \\
\text { traffic }\end{array}$ & 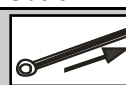 & 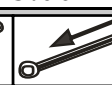 & C & & & \\
\hline A. komerc. & 23 & 18 & 34 & 27 & 32 & 45 \\
\hline BUS & 47 & 36 & 41 & 42 & 48 & 40 \\
\hline Ped/seat. LA & 0.4 & 0.44 & 0.6 & 0.6 & 0.52 & 0.64 \\
\hline Pedestrians & 551 & 197 & 217 & 295 & 213 & 272 \\
\hline Bicycles & 0 & 0 & 0 & 0 & 0 & 0 \\
\hline $\mathbf{A U}$ & 1231 & 1476 & 1030 & 1002 & 1150 & 1242 \\
\hline$\% \mathrm{AR}$ & 0.06 & 0.04 & 0.07 & 0.07 & 0.07 & 0.07 \\
\hline
\end{tabular}

Street "Fehmi Lladrovci" has a symmetry of cross section profile of the road holding a traffic separator, two lanes for direction movement traffic and sidewalks on both sides of the road, which owns total road width of $25 \mathrm{~m}$. In Figure 1 is shown the contents of the cross section profile of the road with its dimensions.

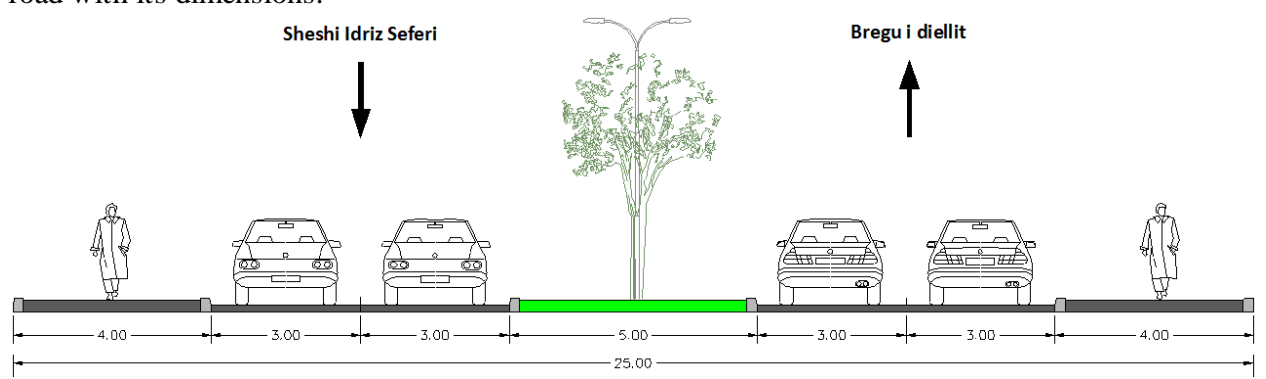

Fig. 1. Cross section of the road "Fehmi Lladrovci".

\section{Calculation of multimodal le vel of service for the segment of the road}

By applying the equations mentioned above is calculated the level of service for segment of the road "Fehmi Lladrovci", where each variable in which required equations are applied to the data segment of the road, which due to the volume of the present paper is not all descriptions of variables in order to see performance results benefited from these calculations. Calculations were made for two cases, in the first case calculation is made for multimodal level of service for current profile that owns the road, and in the second calculation is made multimodal level service for all of the recommended route which possesses the same actual road width but has a different disposition in relation to the current 
situation. From this analy sis the profile reshuffle was intended to achieve optimal value service to all modes of traffic. In tabular form and schematic will be presented the results obtained for the current cross section profile and the cross section profile of the recommended route in which are identified the changes for multimodal level of service.

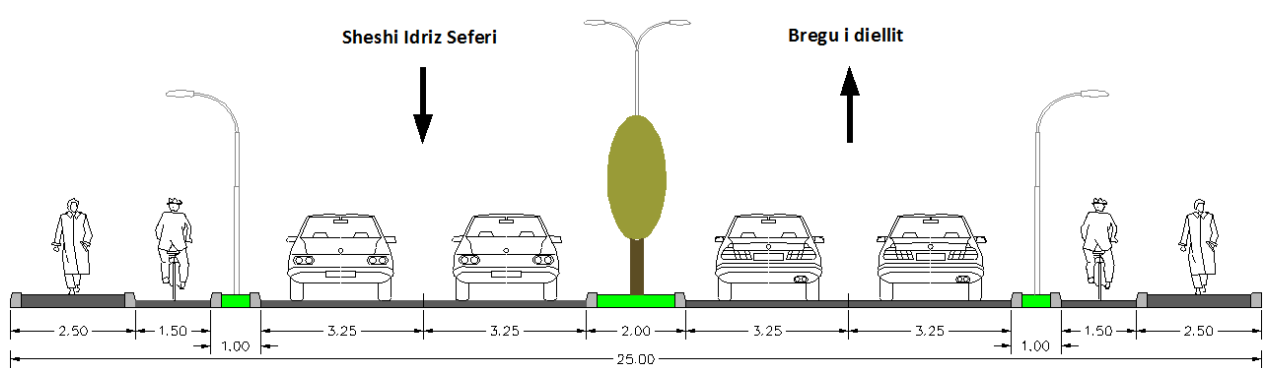

Fig. 2. Recommended cross section profile for the road "Fehmi Lladrovci".

Table 4. Multimodal level of service to the direction of "Bregu i diellit".

\begin{tabular}{|c|c|c|c|c|c|}
\hline Street & \multicolumn{2}{|c|}{ Vehicles } & Public & Bicycles & Pedestrians \\
\hline $\begin{array}{c}\text { "Fehmi } \\
\text { Lladrovci" }\end{array}$ & NCHRP & HCM2010 & transport & & \\
\hline LOS & $\mathbf{C}$ & B & $\mathbf{A}$ & $\mathbf{F}$ & $\mathrm{C}$ \\
\hline Current Profile & 3.72 & 17.47 & 1.89 & 5.06 & 3.25 \\
\hline LOS & $\mathrm{C}$ & B & $\mathbf{A}$ & $\mathbf{A}$ & B \\
\hline $\begin{array}{l}\text { Recommended } \\
\text { proffle }\end{array}$ & 3.52 & 17.47 & 1.80 & 1.84 & 2.62 \\
\hline
\end{tabular}

Table 5. Multimodal level of service to the direction of "Sheshi Idriz Seferi".

\begin{tabular}{cccccc}
\hline $\begin{array}{c}\text { Street } \\
\text { "Fehmi } \\
\text { Lladrovci" }\end{array}$ & \multicolumn{2}{c}{ Vehicles } & $\begin{array}{c}\text { Public } \\
\text { transport }\end{array}$ & Bicycles & Pedestrians \\
\cline { 2 - 5 } LOS & NCHRP & HCM2010 & & & \\
\hline Current profile & $\mathbf{3 . 7 2}$ & $\mathbf{1 9 . 7 1}$ & $\mathbf{1 . 9 1}$ & $\mathbf{4 . 9 9}$ & $\mathbf{3 . 3 8}$ \\
\hline LOS & $\mathrm{C}$ & $\mathbf{C}$ & $\mathbf{A}$ & $\mathbf{A}$ & $\mathbf{B}$ \\
Recommended & 3.52 & 18.97 & 1.82 & 1.77 & 2.75 \\
proffle & & & & & \\
\hline
\end{tabular}

In figure 3 is made in the presentation of the results obtained for multimodal level of service at which observed changes in the level of service under the current profile and the profile of the recommended route. Within the presentation of the level of service for vehicles is presented only the result calculated by HCM 2010 which model takes into account parameters geometric path and intensity of traffic, as opposed to the model according to NCHRP's not taking into consideration the parameters of intensity of traffic for vehicles. 


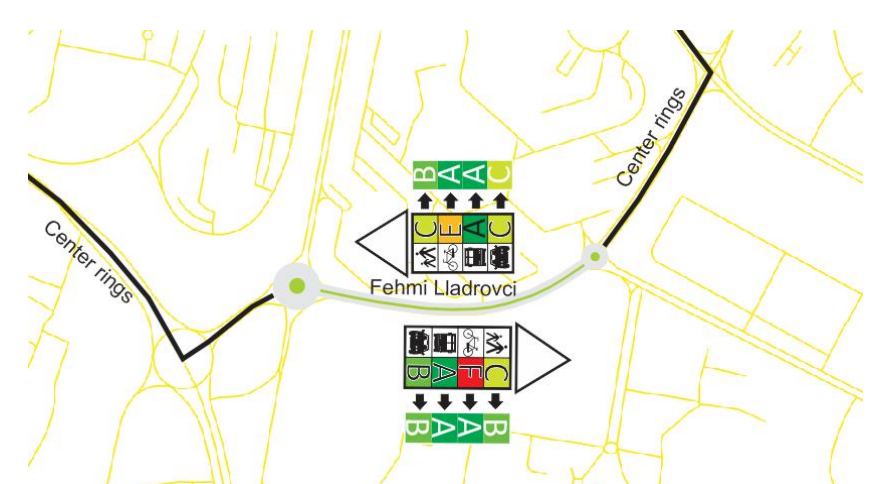

Fig. 3 Schematic representation of multimodal level of service for the urrent profile and the profile of recommended road "Fehmi Lladrovci" in Pristina.

\section{Conclusion}

In results obtained was identified multimodal level of service for current road conditions and for recommended cross section profile of the road. From these results are noticed changes that the same width of cross section and same intensity of traffic is at best take advantage of the service to the recommended cross section road profile. From this profile are created more favorable conditions for the moves with all modes of traffic in particular integration path for bicy cles and phy sically separating the roadside. This analysis of the profile of the segment of the road "Fehmi Lladrovci" can serve as elements for the planning of this profile across the central ring of the city as one of the main roads with heavy traffic, by which will create optimal conditions and opportunity the selection of the model for the movements. For urban roads category and importance as the road "Fehmi Lladrovci" in order to create the conditions to all participants in traffic, a need planning their content such possessing besides paths for vehicles and sidewalks have also bicycles path, necessary services for public transport and depending on the intensity of the flow lines also possess special lane for public transport. Therefore, as an influential factor in the increase of multimodal level of service are creating conditions geometric of the road in order to accommodate all participants in traffic with the contents urban areas with the possibility of selecting the model for traffic depending on the needs and desires, through which achieved reduction of the use of motor vehicles, positive impacts on the environment, traffic more attractive and safer.

\section{References}

1. NCHRP (National Cooperative Highway Research Program), Field Test Results of the Multimodal Level of Service Analy sis for Urban Streets, January 2010

2. NCHRP (National Cooperative Highway Research Program), Report 616, Multimodal Level of Service Analysis for Urban Streets, Transportation Research Board (may 2008)

3. HCM 2010, Urban Street Concepts: Pedestrian, Bicycle, and Transit.

4. Dr.sc. Nijazi Ibrahimi, Mr.sc. Mevlan Bixhaku: "Kapaciteti dhe niveli i shërbimit i infrastrukturës rrugore”, Prishtinë 2010,

5. MSc. Makfiret Abdullahu "Analiza e nivelit multimodal të shërbimit për rrugët urbane B, Muharrem Fejza dhe Fehmi Lladrovci në Prishtinë”.

6. Dr.sc. Shkelqim Zeqo Planet Urbane të transportit, Tiranë 2008

7. James Oliver Ensley "Application of Highway Capacity Manual 2010 Level-of-Service Methodologies for Planning Deficiency Analysis" " Master's Thesis, University of Tennessee, 2012.

8. The 2010 Highway Capacity Manual (2010 Highway Capacity Manual, June 2011)

9. Quality/Level of Service Handbook, state of Florida department of transportation 2013.

10. Complete Streets and Multimodal Level of Service, Bill Cisco, P.E. Dowling Associates, Inc 